\title{
DEVELOPMENT OF HEAT EXCHANGE REACTOR FOR PREPARATION OF AIR-FUEL MIXTURE IN SPARK IGNITION ENGINE
}

\author{
Veljo Raide, Risto Ilves, Arne Kuut, Juri Olt \\ Estonian University of Life Sciences, Estonia \\ veljo.raide@student.emu.ee, risto.ilves@emu.ee, arne.kuut@emu.ee,jyri.olt@emu.ee
}

\begin{abstract}
Hazardous components, such as NOx, $\mathrm{CO}$ and $\mathrm{HC}$, in the spark ignition engine exhaust gases may cause serious consequences for human health. The hazardous components in the engine exhaust gases and thermal losses resulting from the engine work can be reduced to a great extent. Energy is released from the system in the form of heat, which use in preparation of the air-fuel mixture has a significant effect on the combustion process. The aim of the article is to, firstly, give an overview of the design and development processes of a heat exchange reactor on a four stroke spark ignition engine, and, secondly, to analyse the effect of a heat exchanger on the engine output parameters. In this research, a heat exchanger is fitted on a four stroke internal combustion engine-generator. The prototype of the heat exchanger is designed and tested. The influence of the heat exchanger on the engine work parameters is outlined and the problems are described and discussed. The results of prototyping indicate that a heat exchange reactor on a four stroke engine reduces harmful emissions of the test engine. More precisely, $\mathrm{CO}$ emissions decrease, when preheated air-fuel mixture is formed and directed into the spark ignition engine. The existing calculation models of the heat exchanger give inaccurate results of heat exchanger parameters. Based on the abovementioned, effective engine work with a heat exchanger needs further development.
\end{abstract}

Keywords: exhaust reduction, engine efficiency, heat exchanger.

\section{Introduction}

Consistent pollution of the human environment and the Earth's atmosphere is one of the main reasons of global warming. The main cause of the rapid increase in global warming is carbon dioxide and other greenhouse gases caused by human activity resulting from combustion of fossil fuels. The increasing use of fossil fuels such as petroleum or natural gas in the transport sector and the increasing energy needs of people have created a situation, where traditional fuels are being gradually replaced with alternative fuels, including biofuels [1-5]. The use of biofuels does not solve all the environmental pollution aspects related to the internal combustion engines. Besides the reduction of pollution, it is also important to use fuels more efficiently [6]. More efficient use of biofuels in internal combustion engines has been studied in various ways, including via development of fuel mixture preparation and supply systems [7-9]. In addition to modification of fuel supply systems there are different possibilities for better fuel combustion and preparation. One of the solutions worth mentioning is the free piston engines [10] and technical solutions based on the vortex effect and heat exchange, including thermoelectric systems, as additional systems. With the vortex effect based solutions diesel engines are able to significantly decrease the proportion of $\mathrm{NO}_{\mathrm{X}}$ and fine particles in the exhaust gases and reduce heat pollution caused by the high temperature of exhaust gases. Due to the fact that exhaust gases still contain fine particles a longer circulation of exhaust gases will clog the vortex reactor parts. Blockages and depositions prevent creation of the vortex effect [11]. This problem can be solved using heat exchange, where the fuel mixture and exhaust gases flow in separate channels. Depending on the heat exchange area and the flow rate and temperatures of gases, it is possible to achieve significant use of the residual heat from the internal combustion engine and a lower amount of residues in exhaust gases [12-16]. The heat exchange systems that are installed to internal combustion engines vary in terms of shape as well as operating principles. Known solutions include partial [17] and complete heat use solutions [18; 19].

Most popular heat exchangers are plate and tubeshape heat exchangers. In terms of construction these are air-to-liquid, air-to-air and liquid-to-liquid type exchangers. A compact plate heat exchanger, which is capable of withstanding temperatures up to $650{ }^{\circ} \mathrm{C}$ and engine exhaust gas pressure up to 772 $\mathrm{kPa}$, is available, but heat exchangers with suitable parameters are difficult to find for engines with low cubic capacity. In addition, the effect of fuel supply systems based on heat exchange has not been studied in engines with low cubic capacity. In case of a heat exchange based fuel supply system, thermal energy from the exhaust gases is used for partial preparation of the fuel mixture with a tubeshape heat exchanger. Requirements for modelling the feed and heat exchange system were as follows: 
1. size of the system to be developed must be suitable for the test engine $\left(50-250 \mathrm{~cm}^{3}\right)$;

2. system must allow changing the efficiency of heat transfer;

3. system must provide a suitable fuel mixture for running the engine;

4. system must allow running the engine at different loads;

5. system must allow using different types of fuel;

6. system must allow fine-tuning the engine.

This research focuses on product development. The purpose of this article was to provide an overview of the development and development stages of the heat exchange based fuel supply system for internal combustion engines with low cubic capacity and spark-ignition. In addition to development results, the article also provides $\mathrm{CO}$ data measured in exhaust gases at different engine loads using unleaded petrol 95. The performance and efficiency of the heat exchange based fuel supply system is further inspected in the patent document US 5794601.

\section{Materials and methods}

Development of the heat exchange system was started by following the product development principles [20] and it included the following stages:

1. wording and generalising the problem that needs a solution;

2. generating and selecting ideas and finding similar conceptual solutions for the problem in question;

3. analysing and synthesising the selected conceptual solutions;

4. selecting the best technical solution according to the problem.

The test device to be modelled, Fig. 1, has been designed so that when the internal combustion engine is started, negative pressure is created in the fuel supply system parts 12,11, 2 and 6, thus negative pressure is created in the fuel tank 5 and heat exchanger 1, provided that the valve 9 is closed and the valve 8 is minimally open. Negative pressure causes suction of the required air from the exhaust pipe 10 through the fuel tank and fuel. The sucked air flows through the pre-filter 6 and breaks larger air bubbles that are created, when the air passes through fuel, ensuring better fuel evaporation. The evaporated fuel is transferred from the fine particle filter 7 to the heat exchanger.

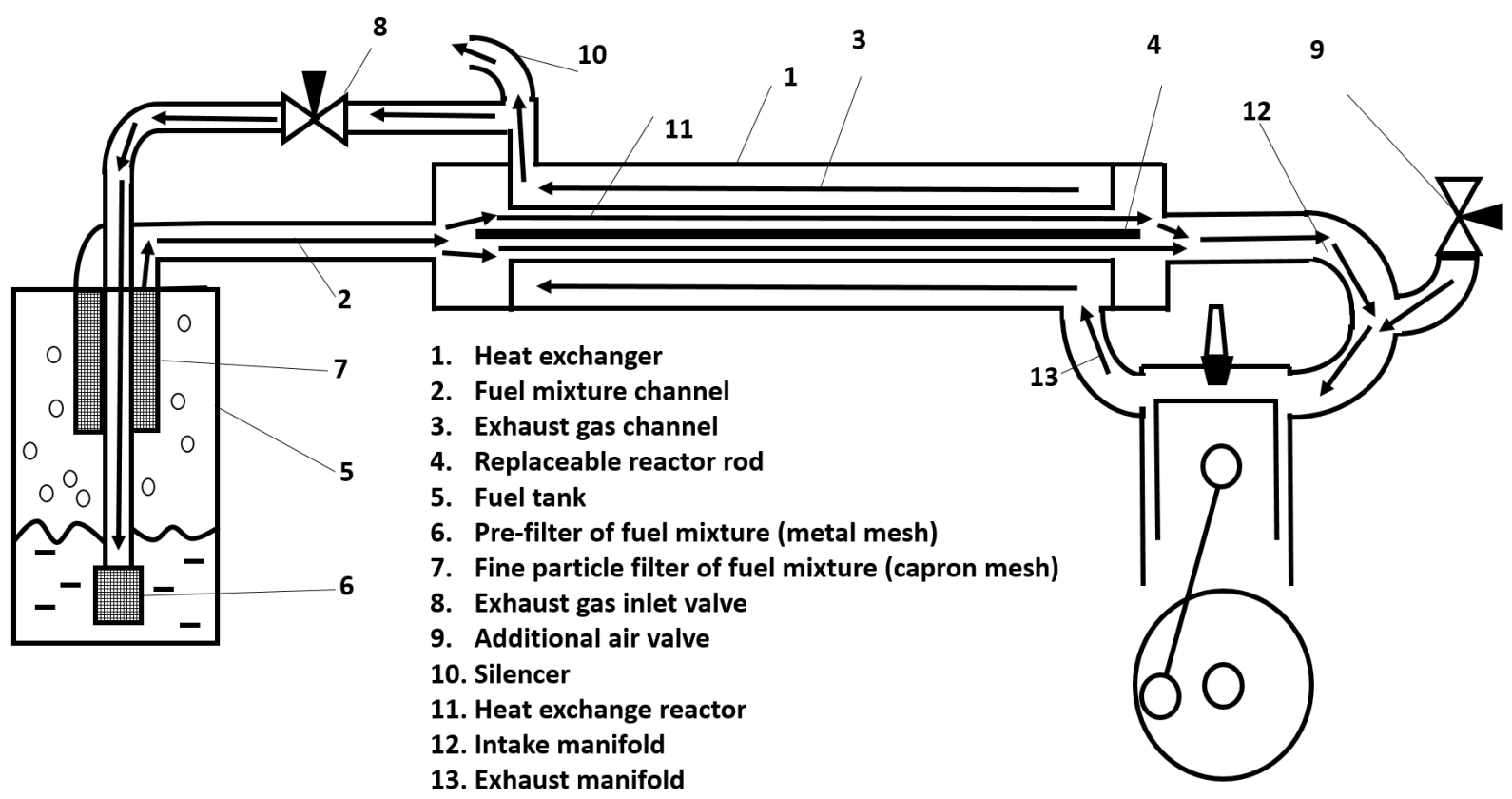

Fig. 1. Principle schematic of engine equipped with fuel supply system based on heat exchange principle

The evaporated fuel flows in the heat exchanger 1 via the fuel mixture channel 2 into the heat exchanger reactor 11, which includes a reactor rod 4 at the centre. The purpose of the rod 4 is to press fuel mixture against the heat exchanger partition wall, which ensures more efficient heat transfer from 
exhaust gases to evaporated fuel. The exhaust gases $3\left(630-650^{\circ} \mathrm{C}\right)$ flow in the opposite direction to the fuel mixtures in the reactor 11 . As a result of operation of the heat exchanger the exhaust gas cools and rarefies and the fuel mixture gets hotter and expands. The heated fuel mixture is sucked to the intake manifold 12 by negative pressure created by the internal combustion engine and, depending on the engine load, the required additional air is supplied to the intake manifold via the valve 9 . The heated fuel mixture and additional air are sucked to the internal combustion engine cylinder and ignited.

Based on the engine's technical data and settings the development must take into consideration certain preliminary technical restrictions [21]. For a spark-ignition internal combustion engine it is possible to use two types of heat exchangers, i.e. tubeshape and plate heat exchanger [18]. Development of a tubeshape heat exchanger requires in particular the identification of problems that may occur when making improvements to the fuel mixture preparation system of the spark-ignition internal combustion engine. Plate heat exchanger allows stable heat exchange between the engine's exhaust gases and fuel mixtures. Plate heat exchanger is somewhat more efficient, but the tubeshape solution is easier to make and maintain during exploitation [17]. In case of tubeshape solution, it is also possible to use replaceable reactor rods, Fig. 1, p. 4, allowing to change the efficiency of heat transfer and thus ensure a more efficient performance of the internal combustion engine.

By adding the heat exchange system to the fuel mixture preparation system of the engine it is possible to use different fuels without the need to make significant changes to the construction of the factory-made engine. The specific solution of each heat exchange system depends on its application. The fuel supply system based on the heat exchange principle can be divided into three types. First is the air-to-fuel type system. Fuel mixture is preheated in the reactor of the heat exchanger and the additional air required for engine operation is added directly to the intake manifold. Second is the airto-fuel and partial exhaust gas type system. Exhaust gases are directed through the fuel tank to the heat exchanger in order to preheat the fuel. Fuel mixture is then directed through the heat exchanger to the engine cylinder. For the heat exchange systems mentioned above different variants of fuel preparation systems, modified carburation, injection and fuel pre-evaporation principle in the tank are used. Description of the pre-evaporation solution of the heat exchange system is provided in the patent document US 5794601, explaining the preparation method of the engine's fuel mixture and constructive solution and operation of the device in greater detail. Regarding the previously specified requirements a tubeshape heat exchanger is used together with a new fuel mixture system in this research, since the selected heat exchanger allows to change the efficiency of heat transfer. The efficiency of heat transfer is changed with reactor rods by adjusting the clearance in the reactor's fuel mixture channel to ensure optimal operating mode.

By using various diameter reactor rods it is possible to optimise the expansion of fuel mixture gases resulting from heat exchange. For the test engine a fuel tank with pre-evaporation was used. Additional air required for engine operation was added directly to the intake manifold. The air-fuel mixture and exhaust gas flow as well as underpressure in the fuel tank and expansion of fuel gases in the heat exchanger must be optimal. Otherwise, the power indicators of the internal combustion engine decrease and the amount of hazardous substances in the engine exhaust gases increases.

Test devices included a 2-stroke (LTE145) and a 4-stroke (DB3500CL) air-cooled spark-ignition engine generator, Fig. 3, Fig. 5. Main factory data of the 2-stroke engine: stroke $40 \mathrm{~mm}$, cylinder capacity $63 \mathrm{~cm}^{3}$ and maximum power $1.5 \mathrm{~kW}, 3000 \mathrm{rpm}$. Main factory data of the 4-stroke engine: cylinder capacity $208 \mathrm{~cm}^{3}$, cylinder diameter $69.9 \mathrm{~mm}$, stroke $55.6 \mathrm{~mm}$ and maximum power $3.6 \mathrm{~kW}$, $3000 \mathrm{rpm}$. These engine generators were selected as test devices, since it was technically better to change and accurately maintain the generator loads in case of this solution. Electric bulbs were used as the controlled load. The fuel used was regular unleaded petrol 95. Engine tests were carried out at loads 500, 1000, 1500 and 2000W. During testing of the fuel supply system the exhaust gas emission was measured with the device Bosch BEA 350 at generator loads 500W and 1000W. During engine tests the carbon monoxide (CO) content in the exhaust gas was measured and a total of 21 measurements were obtained. Data were processed in MS Excel and averaged carbon monoxide (CO) results are presented. 


\section{Results and discussion}

Development of the heat exchange based fuel supply system was divided into two stages. The first stage included selecting a suitable fuel supply system solution and building a test device for a 2-stroke engine. This stage included the following activities:

1. selecting the initial heat exchanger concept and making a model;

2. selecting the fuel tank concept and making a model;

3. preparing technical drawings;

4. building the heat exchanger;

5. building the fuel tank;

6. installing the modified fuel supply system to the 2-stroke engine;

7. testing the engine.

For building a heat exchanger, a model was made, Fig. 2, and drawings were prepared. Then the heat exchanger was built, Fig. 4-A. First problems occurred while building the heat exchangers, depending on the selected stainless material and the pipes of the designed reactor's fuel mixture channel warped and prevented free movement of the reactor rods. In order to solve this structural problem a steel weld pipe was selected as the fuel mixture channel, the channels of which broke during treatment, Fig. 4-B. The reason for this was that the wall of the fuel mixture channel pipes was too thin. A suitable fuel mixture channel for the reactor, Fig. 4-C, was a drawn pipe made of steel E235-N (St 37.4) that ensured the treatment process with suitable accuracy. A heat exchanger was built that included four fuel mixture channels with a total cross-sectional area of $40.84 \mathrm{~mm}^{2}$ and the channel length of $300 \mathrm{~mm}$. The components of the fuel supply system above mentioned were assembled and installed to a 2-stroke engine.

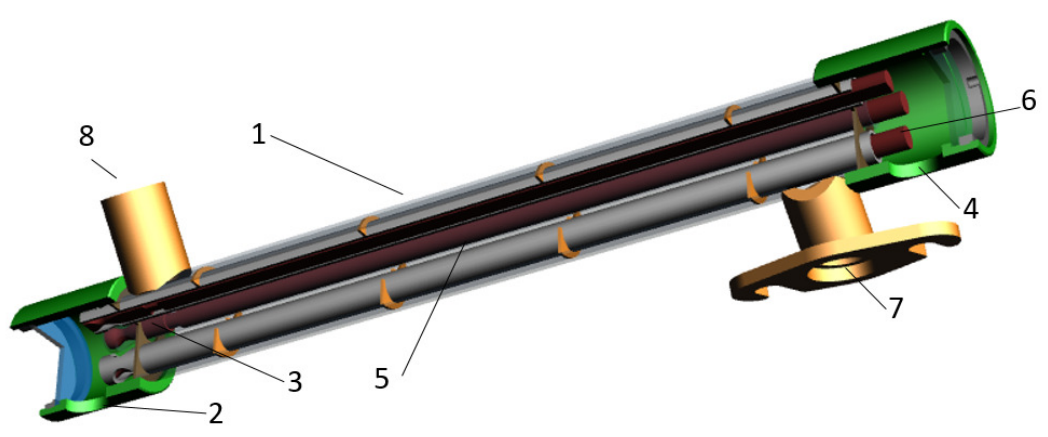

1. Heat exchanger

2. Fuel mixture inlet

3. Fuel mixture channel

4. Pre-heated fuel mixture outlet

5. Exhaust gas channel

6. Replaceable reactor rod

7. Exhaust gas inlet

8. Exhaust gas outlet

Fig. 2. Initial model of heat exchanger

Upon starting the 2-stroke engine a problem occurred with negative pressure in the fuel tank. More specifically, the built fuel tank was too large for creating sufficient negative pressure in the fuel tank for the evaporated fuel to reach the engine. Therefore, a new fuel tank was developed, Fig. 4-E, the working principle of which complied with the initial design and which was 4 times smaller than the original tank. After changing the fuel tank the engine started. During engine operation it was discovered that the data in the patent document US 5794601 about this solution being suitable for 2stroke engines is not correct. After 12 minutes of operation problems occurred with lubrication of the 2-stroke internal combustion engine. As a result of evaporation the oil-petrol mixture in the fuel tank cooled and during evaporation lighter fractions were separated from the fuel, while heavier fuel fractions together with engine oil were left in the fuel tank. According to the data in the patent document US 5794601, it may be expected that the oil added to the fuel would evaporate together with the fuel and thus ensure lubrication of the engine. The problem that occurred during the fuel supply system development can be solved in two ways: 1) by improving the engine with an additional lubrication system; 2) by using a 4-stroke engine, which is lubricated via crankcase.

In the second stage a 4-stroke engine was selected, since the fuel supply system based on the designed heat exchange was suitable for up to $250 \mathrm{~cm}^{3}$ engines and building a lubrication system for a 2 -stroke engine is a complicated process. The second stage of the fuel supply system development included studying heat exchange processes and developing the existing test device. The second stage included the following activities. 
1. installing the test device on the test engine;

2. testing the test device on the engine;

3. mapping the occurred problems and improving the fuel supply system;

4. performing engine tests.

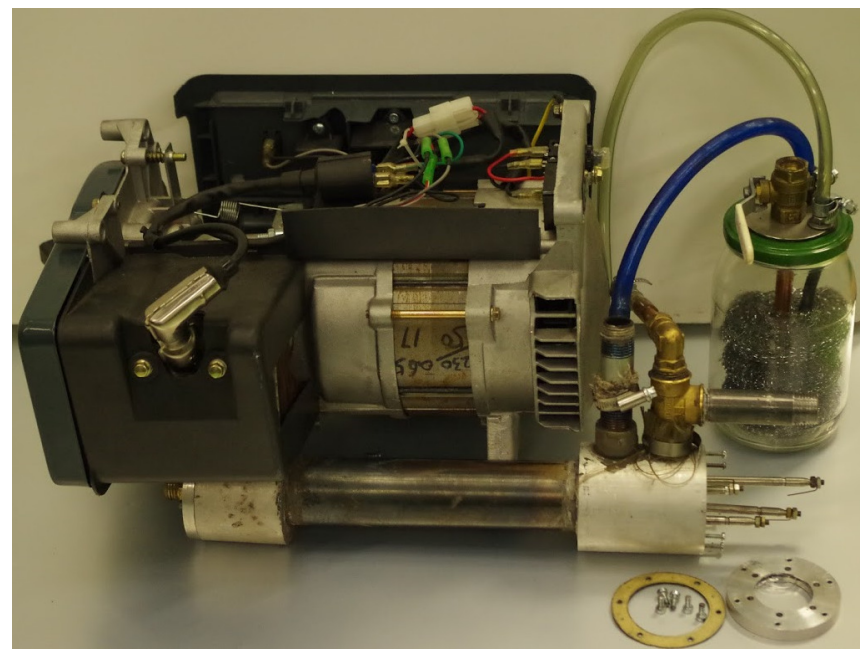

Fig. 3. View of fuel supply system based on designed heat exchange on 2-stroke engine

A heat exchanger, Fig. 4-C, and a fuel tank, Fig. 4-E, were installed to the test engine, Fig. 5. The engine started without problems, operated at low loads and allowed applying $500 \mathrm{~W}$ load to the generator. When the load was increased to $1000 \mathrm{~W}$, problems occurred. The pre-filter and fine particle filter of the fuel tank were unable to sufficiently stabilise the fuel flow in the tank, causing the liquid fuel to enter the reactor. Liquid fuel that entered the reactor impaired its operation. The reason for the occurred problem was the capacity of the selected fuel tank (1 litre) and the small distance between the fuel level and the fine particle filter. The 4-stroke test engine $\left(208 \mathrm{~cm}^{3}\right)$ created high negative pressure in the fuel tank and caused the fuel to enter the heat exchanger. For the fuel supply system of the test engine the initially designed 4 litre fuel tank, Fig. 4-F, was installed. The replaced fuel tank allowed engine operation without problems and applying $1000 \mathrm{~W}$ load to the generator. At generator load of $1500 \mathrm{~W}$ problems occurred with fuel feed. More precisely, the problem was keeping the rotational speed of the crankshaft at $n_{e}=3000 \mathrm{rpm}$. The engine operated with low performance fuel mixture, since the fuel supply system could not provide the amount of fuel required for operation. In order to solve the problem, reactor rods with a diameter of $6 \mathrm{~mm}$ were replaced with rods with a diameter of $5 \mathrm{~mm}$. This solution increased the cross-sectional area of the fuel mixture channels to $75.4 \mathrm{~mm}^{2}$.

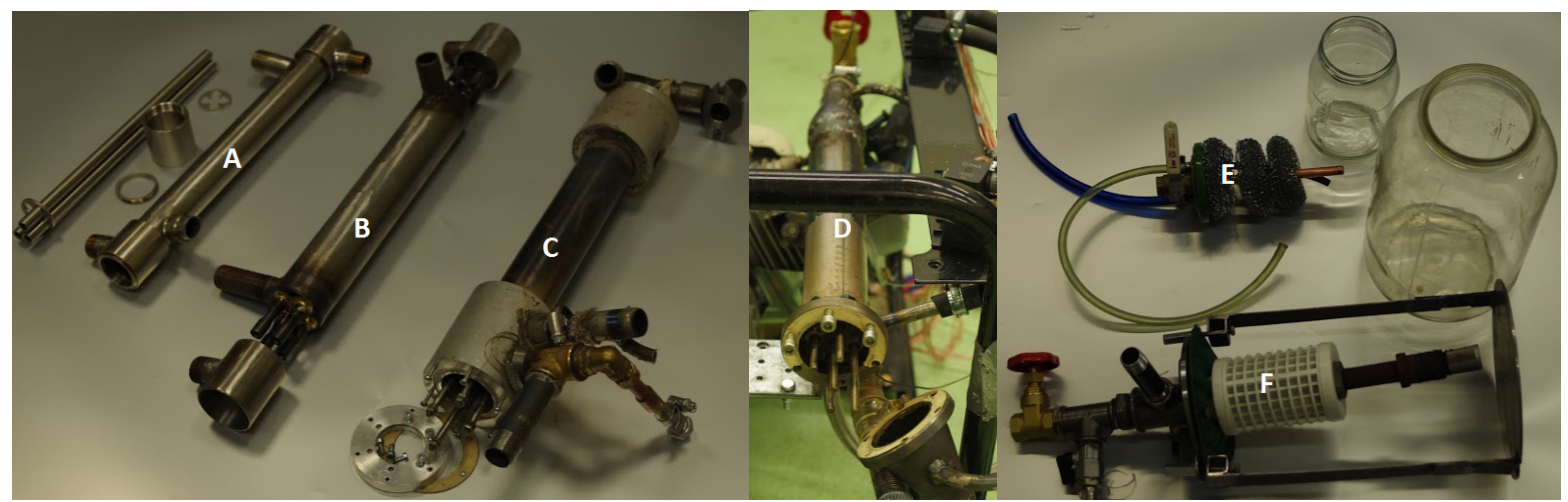

Fig. 4. Heat exchanger prototypes (A, B, C, D) and fuel tanks (E, F)

The engine with a modified fuel supply system did not operate steadily at the load of $1500 \mathrm{~W}$ and stopped after a certain period of time. The problem was caused by cooling of the fuel in the fuel tank, which resulted in poor evaporation of the fuel. In order to solve the problem, the cross-sectional area of the channel, Fig. 1, between the fuel tank of the fuel supply system and the heat exchanger was increased $\left(221.6 \mathrm{~mm}^{2}\right)$ and exhaust gases were also directed to the fuel tank. Directing the exhaust gases to the fuel tank increases fuel temperature in the fuel tank and ensures more efficient 
evaporation of the fuel. With the improvements a steady engine operation was achieved at the load of $1500 \mathrm{~W}$ and complete evaporation of fuel in the tank. At the load of $2000 \mathrm{~W}$, the generator did not operate steadily and required constant adjustment of rotational speed. Since this problem also occurred at the load of $1500 \mathrm{~W}$, it can be concluded that this fuel supply system is unable to supply the engine with sufficient amount of fuel. In addition to the previously described, a connection problem occurred as a result of engine vibrations - the heat-resistant silicone failed and the reactor parts started to vibrate. Therefore, it was decided to develop a new heat exchanger with five channels, where the cross-sectional area of the fuel mixture channel of the heat exchanger, Fig. 1, was increased to 129.6 $\mathrm{mm}^{2}$. It was assembled by welding. For the heat exchange in the fuel mixture channel a $450 \mathrm{~mm}$ usable total length was selected. The channel diameter of the internal combustion engine was increased by 1.5 times. As a result of improvements the engine-generator operated at a load of $2000 \mathrm{~W}$ steadily for a while, but then required additional adjustment. The reason for this was uneven evaporation of fuel in the tank, where light fractions evaporated before heavy fractions. In order to solve the problem, the fuel supply system needs to be improved with a centrifugal governor that allows regulating the fuel mixture depending on the fuel fraction applied to the engine. During engine tests it was studied, how the heated fuel mixture affects the engine's exhaust gas emission.

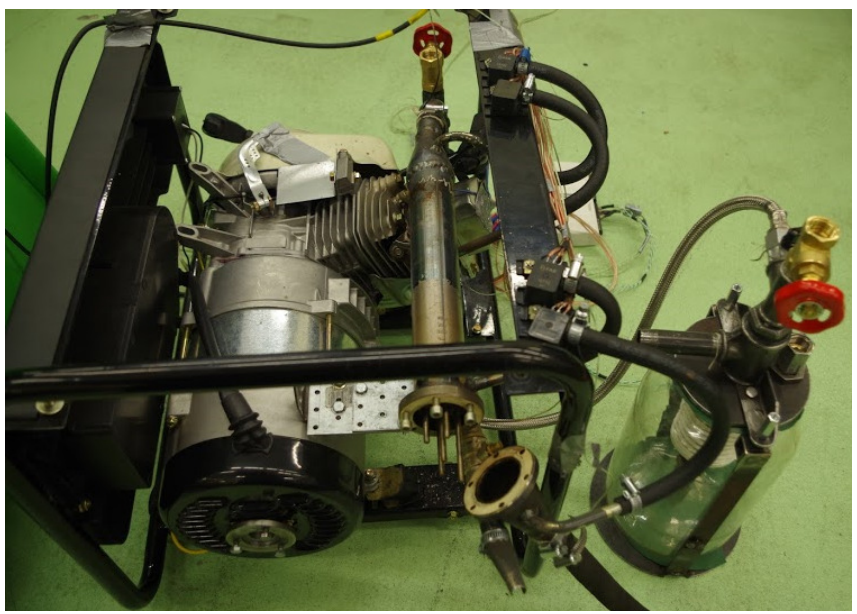

Fig. 5. View of fuel supply system based on designed heat exchange on 4-stroke engine

Basic technical data of the heat exchanger of the fuel supply system that was used in the engine tests are shown in Table 1.

Basic data of technical components of heat exchanger

Table 1

\begin{tabular}{|c|c|c|}
\hline Technical component & Unit & Value \\
\hline Heat exchanger's operating part length & $\mathrm{mm}$ & 450 \\
\hline Cross-sectional area of exhaust gas flow & $\mathrm{mm}^{2}$ & 1493 \\
\hline Internal diameter of the internal pipe & $\mathrm{mm}$ & 7 \\
\hline Reactor rod diameter (5 pcs) & $\mathrm{mm}$ & 5 \\
\hline Cross-sectional area of fuel mixture flow & $\mathrm{mm}^{2}$ & 129.6 \\
\hline
\end{tabular}

When regulating the fuel supply system with a heat exchanger, there is a delay that should be taken into consideration. The delay makes adjusting the fuel supply system complicated, especially at higher loads (1500-2000 W). At lower loads $(0-1000 \mathrm{~W})$ there were no problems during adjustment of the fuel system. The measurement data of carbon monoxide that was measured during the engine tests are shown in Fig. 6.

Figure 6 shows that carbon monoxide content in exhaust gases at loads $500 \mathrm{~W}$ and $1000 \mathrm{~W}$ decreases significantly. When using the developed fuel supply system at a load of $500 \mathrm{~W}$, the CO content decreased by $74.4 \%$. At a load of $1000 \mathrm{~W}$ this content decreased by $93.27 \%$. During testing it was also discovered that the engine vibrations at different loads are noticeably lower compared to using the engine's original fuel supply system. 


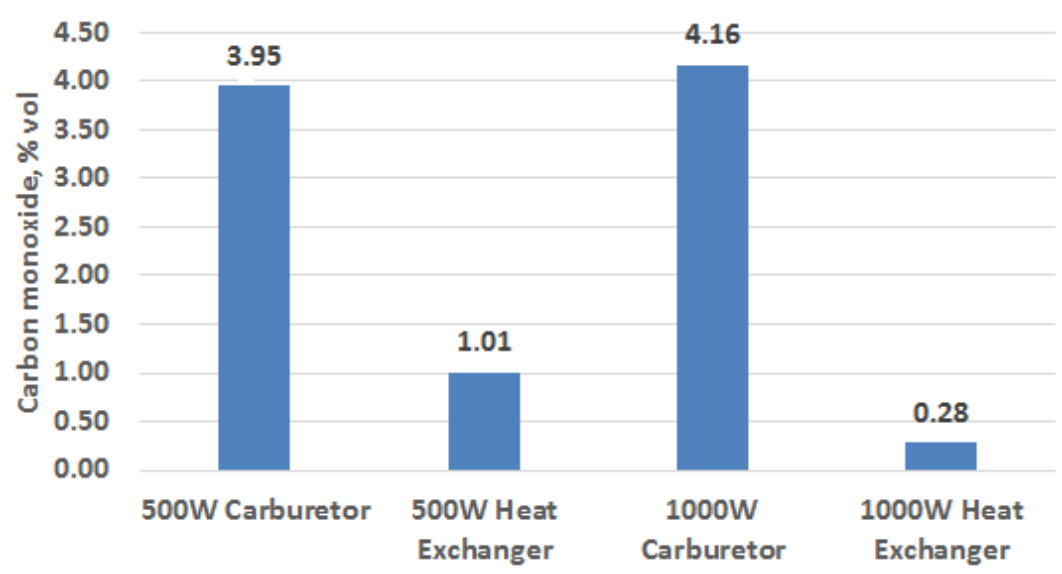

Fig. 6. Carbon monoxide (CO) content in exhaust gases for engine equipped with carburettor and heat exchange based fuel supply system at generator loads $500 \mathrm{~W}$ and $1000 \mathrm{~W}$

\section{Conclusions}

This research describes the development process of the heat exchange based fuel supply system in stages. The development systems are divided in two, for the development of a 2-stroke engine and for the development of a 4-stroke engine.

1. During development of the heat exchange based fuel supply system of a 2-stroke spark-ignition engine the following aspects became evident:

- capacity of the fuel tank must comply with the engine's cubic capacity (large fuel tank capacity is not suitable for an engine with low cubic capacity);

- by increasing the cross-sectional area of the heat exchanger's fuel mixture channel it is possible to apply higher generator loads. It must be considered that it lowers the efficiency of heat transfer;

- technical conditions of the fuel supply system described in the patent document US 5794601 are not suitable for a 2-stroke engine (light fractions evaporate in the fuel tank and heavy fractions such as engine oil do not evaporate).

2. During development of the heat exchange based fuel supply system of a 4-stroke spark-ignition engine the following aspects became evident:

- capacity of the fuel tank must comply with the engine's cubic capacity;

- change in fuel fractions in the fuel tank requires installing an additional centrifugal governor to the fuel preparation system;

- by increasing the cross-sectional area of the fuel channel of the fuel supply system the CO indicators deteriorate at lower loads.

3. In case of the heat exchange based fuel supply system there was a significant drop in the carbon monoxide $(\mathrm{CO})$ content in the engine exhaust gases.

4. The engine vibrations decreased at different loads, when using the fuel supply system based on heat exchange.

\section{References}

[1] Küüt A., Ilves R., Küüt K., Raide V., Ristlaid K., Olt J. Influence of European Union Directives on the Use of Liquid Biofuel in the Transport Sector. Procedia Engineering, 2017, vol. 187, pp. 30-39.

[2] IEA PUBLICATIONS, World Energy Outlook 2008. 9, rue de la Federation, 75739 PARIS Cedex 15, Printed In France By Stedi Media, (612008231P1) ISBN-13: 9789264 04560-6.

[3] Müllerova D., Jablonicky J., Hujo L., Kosiba J. Detection of Emissioon in Combustion Engineś Exhaust. In Machines, Technologies, Materials, 2011, vol.5, no 4, pp. 53-56.

[4] CAMEO Chemicals, URL: https://cameochemicals.noaa.gov/chemical/4050 (04.03.2018).

[5] EPA Health Effects Notebook for Hazardous Air Pollutants. 2015. EPA Air Toxics, Acrolein, URL: https://www.epa.gov/sites/production/files/2016-09/documents/acrolein.pdf (04.03.2018). 
[6] Demirbas A. Green Energy and Technology. In Chapter 3. Biofuels, Pringer Verlag. 2009, pp. 87-101.

[7] Patent EE 05665 B1. Formation method of fuel-air mixture of reciprocating engine and flexiblefuel system. 2013. http://www.epa.ee/ul/doc/valjaanded/patendileht2013_03.pdf

[8] Ilves R., Küüt A., Mikita V., Olt J. The Development of an Additional Fuel Supply System to an Internal Combustion Engine. 8th International DAAAM Baltics Conference, INDUSTRIAL ENGINEERING, April 19-21, 2012, Tallinn, Estonia. http://innomet.ttu.ee/daaam_publications/2012/ilves.pdf (04.03.2018).

[9] Küüt A., Ilves R., Vlasov A., Soots K., Olt J. Impact of Bioethanol Fuel on Output Parameters of Two-stroke Reciprocating Engine. Engineering For Rural Development, May 29-30, 2014. Jelgava, Latvia, pp. 288-295.

[10]Raide V., Ilves R., Küüt A., Küüt K., Olt J. Existing State of Art of free-piston Engines. Agronomy Research, vol. 15 (S1), 2017. pp. 1204-1222.

[11] Kukis V.S., Omelchenko E.A., Raznoshinskaia A.V. Results of Vortex Tube Usage in Diesel Exhaust Gas Recirculation Syste. Procedia Engineering, vol. 129, 2015, pp. 151-155.

[12] Orr B., Akbarzadeh A., Mochizuki M., Singh R. A Review of Car Waste Heat Recovery Systems Utilising Thermoelectric Generators and Heat Pipes. Applied Thermal Engineering, vol. 101, 2016, pp. 490-495.

[13] Kim S., Park S., Kim S., Rhi S.H. A Thermoelectric Generaator Using Engine Coolant for Lightduty Internal Combustion Engine-Powered Vehicles. J. Electron Mater, vol. 40, 2011, pp. 812-816.

[14] Karri M.A., Tcacher B.T., Helenbrook B.T. Exhaust Energy Conversion by Thermoelectric generaator: Two Case Studies. Energy Convers. Manag, vol. 52, 2011, pp. 1596-1611.

[15] Hossain S.N., Bari S. Waste Heat Recovery from Exhaust of a Diesel Generator Set Using Organic Fluids. Procedia Engineering, vol. 90, 2014, pp. 439 - 444.

[16] Hossain S.N., Bari S. Effect of Design-parameters of Heat Exhanger on Recovering Heat from Diesel Engine Using Organic Rankine Cycle. International Conference on Mechanical Engineering, 2011. Dhaka, Bangladesh.

[17] Ghaly A.M., Eldrainy Y.A., El-Maghlany W.M., Yousef A.M. Novel Thermal Throttling Model in Spark ignition Engines: A Way to Replace a Mechanical One. Thermal Science and Engineering Progress, vol. 4, 2017, pp. 223-230.

[18] Bari S., Hossain S.N. Design and Optimization of Compact Heat Exhangers to be Retrofitted into a Vehicle for Heat Recovery from a Diesel Engine. Procedia Engineering, vol. 105, 2015, pp. 472-479.

[19] Hatami M., Ganji D.D., Gorji-Bandpy M. Numerical Study of Finned Type Heat Exhangers for ICEs Exhaust Waste Heat Recovery. Case studies in Thermal Engineering, vol. 4, 2014, pp. 53-64.

[20] Ulrich K.T., S. D. Eppinger S.D. 2000. Product Design and Development. The McGraw-Hill Companies. 358 p.

[21]Pahl G., Beitz W., Feldhusen W.J., Grote K.H. Engineering Design. A systematic Approach. Springler-Verlag, London Limited, 2007, 53 p. 